\title{
Cytogenetic variability in PInus sylvestris L. populations experiencing anthropogenic influence
}

\author{
A. Oudalova, S. Geras'kin, D. Vasiliev and V. Dikarev \\ Russian Institute of Agricultural Radiology and Agroecology, 249030 Obninsk, Russia
}

\begin{abstract}
Pinus sylvestris L. populations growing at the territory affected by nuclear waste storage facilities were monitored in 1997-2002. Cytogenetic damage levels within root meristem of seedlings significantly exceed corresponding controls. Populations experiencing man-caused influence have a higher seeds radioresistance and enlarged cytogenetic variance. These are considered as an indication of adaptation processes in the studied pine populations. An analysis of the structure of ecological-genetical variability is carried out. Changes of two components of the intrapopulational variance were studied in dependence on time and man-caused impact. The first component is engaged to the genetically determined variability of biological characteristics intrinsic for the species and is dominant in studied tree populations. The second is responsible for the variance originating from anthropogenic contamination of the natural habitat. A tendency of destabilizing dynamics and increasing mean values of intraclass correlation coefficient that is a measure of contribution from heterogeneity among trees into total cytogenetical variability is demonstrated under conditions of chronicle technogenic impact on pine populations.
\end{abstract}

\section{INTRODUCTION}

Man-caused pollution has become one of the most significant factors determining biosphere development nowadays. Genetic polymorphism on resistance to external impact is intrinsic in natural populations; subsequent divergence in development and survival of individuals play an important part in a performance of population adaptation to a changed habitatn $[1,2]$. Under chronic stressful impact such as man-made pollution, these processes result in changing value or structure of intrapopulational variability rather than of phenotypic appearance of a species feature [1-7]. An analysis of ecological-genetic structure of variability allows getting an assessment of phenotypic flexibility and adaptive potential of populations having different cenotic significances and survival strategies. A study of edificatory species occupying dominant position in phytocenosis is especially important since any modification of their structure or quantity can cause a significant breach in ecosystem functioning.

The growing quantity of radioactive waste in countries possessing nuclear energy technologies raises a question about their storage and processing. Radioactive waste storage facilities are potentially one of the main sources [8] of hazard for both the public and environment. To study whether natural populations have experienced environmental stress in areas with relatively low levels of pollution, Pinus sylvestris L. populations growing in a vicinity of nuclear facilities in Leningrad region of Russia were monitored in 1997-2002. Preliminary cytogenetical findings were published in [9]. Since than, experimental data have been significantly stocked up. In this work, a study of cytogenetical variability in Scots pine populations experiencing anthropogenic influence is presented. 


\section{MATERIALS AND METHODS}

Detailed description of radioecologic situation in the region was made in [10]. Just mention here that since the early 1970s (an operation period of the main nuclear facility, the 'Radon' Leningrad regional waste processing enterprise (LWPE)), doses absorbed by the biota and population from technogenic radionuclides did not exceed the levels officially adopted as permissible. But, equipment and repositories of radioactive wastes are the main sources of local groundwater pollution. An increased occurrence of rather high levels of radionuclides and other man-caused pollutants (especially heavy metals) has been detected in environmental compartments in the vicinity of the 'Radon' plant [10].

Pine cones were collected in the autumns of 1997 - 2002 from Scots pine trees populations located at the 'Radon' LWPE territory (Population A), in the center of the Sosnovy Bor town at a distance of $5 \mathrm{~km}$ from the Leningrad NPP (Population B) and at a distance of $30 \mathrm{~km}$ from the town (near the settlement of Bolshaya Izhora - reference Population C). Averaged through 6 years $\gamma$-radiation dose rates amounted to $12.6 \mu \mathrm{R} / \mathrm{h}$ in Bolshaya Izhora, $12.8 \mu \mathrm{R} / \mathrm{h}$ in Sosnovy Bor, and $18.8 \mu \mathrm{R} / \mathrm{h}$ at the 'Radon' LWPE territory, as measured with DRG-01T dosimeter at a height of $1 \mathrm{~m}$. Seeds were germinated, and the seedling roots were fixed in first mitosis (at a length of 10-15 mm). Temporary squashed preparations of root apical meristem were made and stained. In each slide, a proportion of cells with aberrations were determined. $2700-16500$ cells at each plot were scored. A portion of the seeds was acutely irradiated with $\gamma$-rays from ${ }^{60} \mathrm{Co}$ (Lutch Irradiator, Latenergo, Latvia) at a dose of $15 \mathrm{~Gy}$, dose rate of $0.6 \mathrm{~Gy} \mathrm{~min}^{-1}$. After irradiation, seeds were germinated and 23 - 55 seedlings for each variant were immediately fixed. More detailed information on methods is given in [9].

To determine a significance of the difference between sample mean values, the Student's $t$-test was applied. For fitting the temporal changes in cytogenetic variance, a regression analysis was used [11]. Snedekor estimation of intraclass correlation coefficient (ICC) was made as described in [12].

Table 1. Aberrant cell frequency in seedling root apical meristem of Scots pine (mean \pm se).

\begin{tabular}{|c|c|c|c|c|c|c|}
\hline \multirow{2}{*}{ Year } & \multicolumn{2}{|c|}{ Population C } & \multicolumn{2}{c|}{ Population B } & \multicolumn{2}{c|}{ Population A } \\
\cline { 2 - 7 } & Cells scored & Aberrant cells, \% & Cells scored & Aberrant cells, \% & Cells scored & Aberrant cells, \% \\
\hline 1997 & 14643 & $0.60 \pm 0.06$ & 12342 & $1.19 \pm 0.10 *$ & 7927 & $1.53 \pm 0.14 *$ \\
\hline 1998 & 12217 & $0.53 \pm 0.07$ & 12832 & $1.30 \pm 0.10 *$ & 9437 & $1.73 \pm 0.13 *$ \\
\hline 1999 & 16482 & $0.57 \pm 0.06$ & 8302 & $1.36 \pm 0.13 *$ & 5613 & $1.73 \pm 0.17 *$ \\
\hline 2000 & 9885 & $0.66 \pm 0.08$ & 3517 & $1.73 \pm 0.22^{*}$ & 2674 & $2.28 \pm 0.29 *$ \\
\hline 2001 & 14007 & $0.69 \pm 0.07$ & 5229 & $1.84 \pm 0.19 *$ & 4355 & $2.18 \pm 0.22 *$ \\
\hline 2002 & 13790 & $0.70 \pm 0.07$ & 5929 & $1.75 \pm 0.17 *$ & 4912 & $2.16 \pm 0.21 *$ \\
\hline
\end{tabular}

Difference from the corresponding reference level is significant, $\mathrm{p}<5 \%$.

Comparison of ICC values was performed both through a confident intervals calculation using simplified Wald's formula and application of z-transformation to Snedekor ICC estimates [12].

\section{RESULTS AND DISCUSSION}

\subsection{Aberrant cells frequency}

Cytogenetic damage levels in Scots pine populations A and B are significantly higher than in the reference population $\mathrm{C}$ (Table 1). These effects could not be attributed to the radiation exposure alone because, at least at the Sosnovy Bor site (population B), dose rates did not notably exceed the reference values through the whole observation period. Thus, the data suggest strongly a presence of some mutagenic contaminants in the environments of pine populations A and B. 
At an analysis of aberration spectra [9], tripolar mitoses, rather rare anomalies, were found in the samples from both populations B and A. Their appearance is possibly linked to spindle damage $[13,14]$. Authors of $[14,15]$ have associated this type of mutations with environment contamination by heavy metals. Indeed, heavy metals are typical aneugenic agents that do not act directly on DNA $[16,17]$, but efficiently induce spindle damage $[18,19]$. This suggests when taken together with the dosemetric data, that the studied area is likely contaminated with genotoxic chemicals.

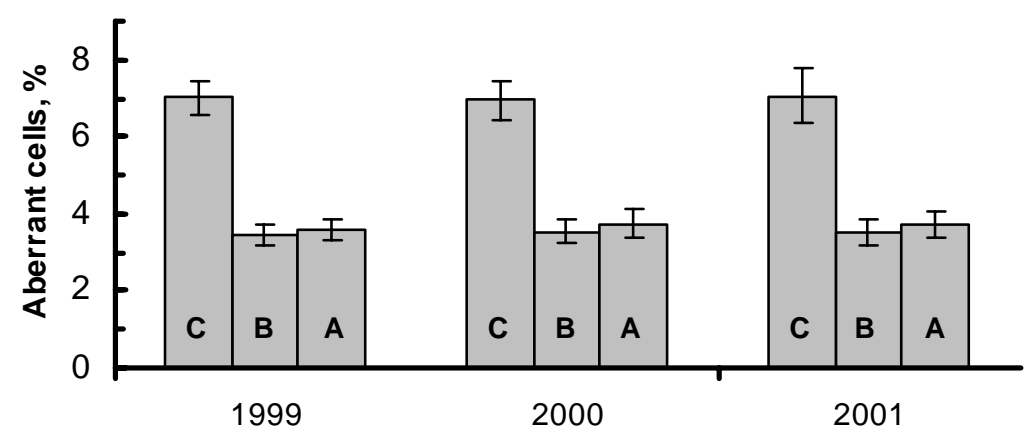

Figure 1. Aberrant cell frequency in the root meristem of Scots pine seedlings grown from seeds exposed to an acute $\gamma$-ray dose of $15 \mathrm{~Gy}$.

\subsection{Radio-adaptation}

The seeds from pine populations A and B appeared to be significantly more resistant to the acute $\gamma$-ray exposure than the reference population $\mathrm{C}$ (Fig. 1).

The so-called "radio-adaptation phenomenon", i.e. an apparent increase in mean radioresistance to an additional, acute $\gamma$-radiation exposure, has been observed as one of the consequences of chronic irradiation in natural populations in the East Urals trail region $[1,20]$. Numerous studies into "radio-adaptation phenomenon" provide the suggestion that it is a selection for changes in repair effectiveness that causes a radioresistance alteration in population. Most investigations confirmed an actual evolution of resistance [1,20-23] have involved plants with relatively short life cycles. A number of pine generations replaced during the 'Radon' LWPE existence are obviously insufficient for natural selection, in the common sense, on repair systems efficiency. One possible explanation of such a rapid adaptation of plant populations within several years relates to a selection on cellular radiosensitivity, i.e. an elimination of sensitive cells and their apparent replacement with more resistant cells [24]. An alternative explanation concerns an induced epigenetic change in the functional genes activity that is heritable over a number of cell generations $[3,25]$.

\subsection{Ecological and genetical variability}

The Scots pine populations A and B, experiencing anthropogenic exposure, showed a significantly increased level of cytogenetic variability, as assessed by value of total variance, in comparison to the reference population (Fig. 2). Besides, variances of the aberrant cells frequencies in the seedling root meristem were found to significantly increase with time in all the three pine populations.

In natural populations, there is a genetically determined polymorphism on resistance to various impacts. At this, an increase of the variability is one of the major adaptive responses to a stressful exposure $[1,3,6]$, because in the case of a severe change to the environment, a population can survive only if at least a part of individuals retains the vitality to produce the offspring. Enlarging spectra of individual responses offer a potentiality to choose the fittest modification among available. 
Consequently, a variability increase indicates an induction of adaptive processes. A terminal selection of response patterns results in the change of mean values of the quantitative traits. Change in variability is often even more sensitive indicator than difference of mean values, especially when adaptation processes are far from finishing.

Total intrapopulational variability can be divided to two components so that the first is genotypically predetermined as intrinsic for a given species, and the second depends on environment conditions. Thus, total cytogenetical variance, SS, can be broken down into its constituent parts:

$$
\mathrm{SS}=\mathrm{SS}_{\mathrm{w}}+\mathrm{SS}_{\mathrm{b}}
$$

where $\mathrm{SS}_{\mathrm{b}}$ - variability between trees, $\mathrm{SS}_{\mathrm{w}}=\Sigma \mathrm{SS}_{\mathrm{i}^{-}}$variability within trees crowns. Proportion and dynamics of these components reveal processes of population adaptation to varying environment.

A value of the first component, $\mathrm{SS}_{\mathrm{w}}$, is calculated from repeated measurements on metameras, i.e. multiply repeated part or organ in the same individual. Seeds collected from the same pine tree stand for metameras. Differences between metameras are supposed to originate from genotype reaction norm on microfluctuations of habitat conditions or random alterations at repeated realizations of metamera structure by the same genotype ('noise'). Such variability within the same genotype is assumed to be mainly genetically predetermined [2]. In the populations examined, metamerical variability, $\mathrm{SS}_{\mathrm{w}}$, of aberrant cells frequency in seedlings root meristem makes above $90 \%$ of total variance, $\mathrm{SS}$, in overwhelming majority of variants (Table 2). In population $\mathrm{C}$, average $\mathrm{SS}_{\mathrm{w}}$ amounts to $93.0 \%$, while in populations B and A, average values are lower (88.2\% and $86.9 \%$, correspondingly).

Table 2. Structure of intrapopulational variability of aberrant cells frequency in root meristem of pine seedlings.

\begin{tabular}{|c|c|c|c|c|c|c|c|c|c|}
\hline \multirow{3}{*}{ Year } & \multicolumn{3}{|c|}{ Population C } & \multicolumn{3}{|c|}{ Population B } & \multicolumn{3}{|c|}{ Population A } \\
\hline & \multirow{2}{*}{$\mathrm{k} / \mathrm{N}$} & $\mathrm{SS}_{\mathrm{w}}$ & $\mathrm{SS}_{\mathrm{b}}$ & \multirow{2}{*}{$\mathrm{k} / \mathrm{N}$} & $\mathrm{SS}_{\mathrm{w}}$ & $\mathrm{SS}_{\mathrm{b}}$ & \multirow{2}{*}{$\mathrm{k} / \mathrm{N}$} & $\mathrm{SS}_{\mathrm{w}}$ & $\mathrm{SS}_{\mathrm{b}}$ \\
\hline & & \multicolumn{2}{|c|}{$\%$ of SS } & & \multicolumn{2}{|c|}{$\%$ of SS } & & \multicolumn{2}{|c|}{$\%$ of SS } \\
\hline 1997 & $6 / 200$ & 93.3 & $6.7 * *$ & $5 / 175$ & 99.1 & 0.9 & $5 / 144$ & 98.9 & 1.1 \\
\hline 1998 & $10 / 277$ & 94.1 & $5.9^{*}$ & $6 / 306$ & 97.5 & 2.5 & $8 / 232$ & 96.4 & 3.6 \\
\hline 1999 & $12 / 155$ & 91.9 & 8.1 & $8 / 78$ & 94.9 & 5.1 & $6 / 50$ & 97.2 & 2.8 \\
\hline 2000 & $9 / 87$ & 93.2 & 6.9 & $8 / 30$ & 64.4 & 35.6 & $6 / 26$ & 73.8 & 26.3 \\
\hline 2001 & $12 / 120$ & 91.0 & 9.0 & $8 / 56$ & 91.0 & 9.0 & $10 / 49$ & 83.6 & 16.4 \\
\hline 2002 & $14 / 118$ & 94.5 & 5.5 & $12 / 67$ & 82.4 & 17.6 & $11 / 52$ & 71.6 & 28.4 \\
\hline
\end{tabular}

$\mathrm{k}$ - number of trees; $\mathrm{N}-$ total number of seedlings. ICC differs from $0: * *-\mathrm{p}<5 \%, *-\mathrm{p}<10 \%$.

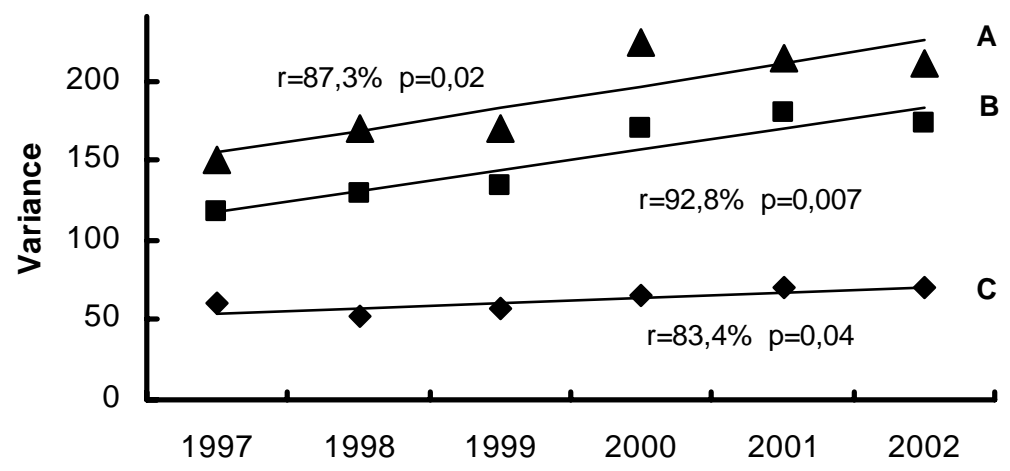

Figure 2. Variances of aberrant cell frequency in seedling root meristem of Scots pine trees. 


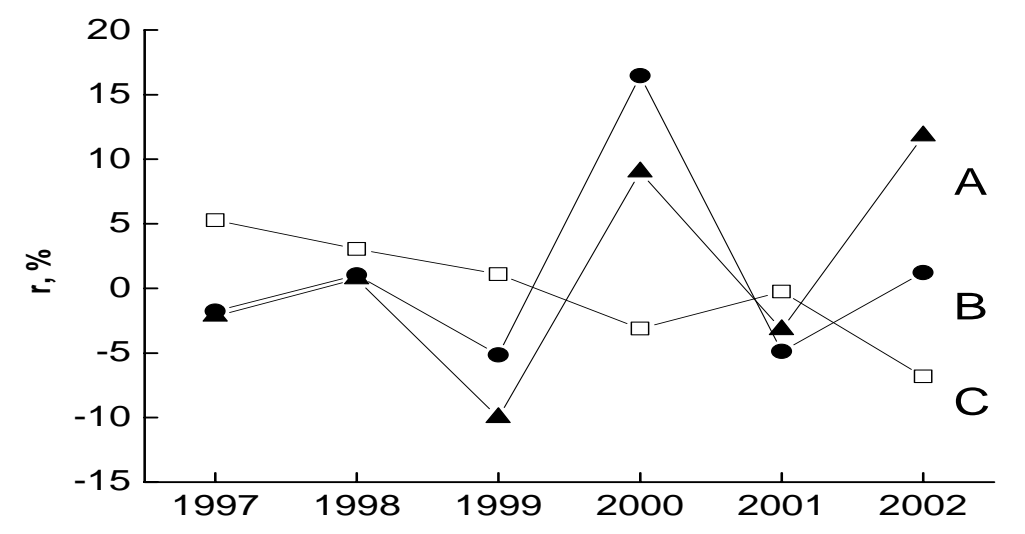

Figure 3. Dynamics of Snedekor estimates of intraclass correlation coefficient in three pine populations.

The second component in formula (1), $\mathrm{SS}_{\mathrm{b}}$, comprises of both genotypical and ecologically caused divergences. After excluding genetically predetermined part, $\mathrm{SS}_{\mathrm{w}}$, from total variance, differences in values of $\mathrm{SS}_{\mathrm{b}}$ between populations are expected to become more apparent. A ratio of intra-tree variance, $\mathrm{SS}_{\mathrm{b}}$, to total value is called $[2,12]$ an intraclass correlation coefficient, $\rho=\mathrm{SS}_{\mathrm{b}} / \mathrm{SS}$. This index shows what proportion of diversity a studied factor, i.e. divergence between trees in population, brings to total variance. Despite high absolute values of ICCs up to $35.6 \%, \rho$ do differ from 0 in two variants only (Table 2), as estimated by F-criteria [12]; that is a contribution of intra-trees difference into total diversity in population appears confident only in population C in 1997 and 1998.

To make comparison of general ICC values, Snedekor estimates of sampling ICC values, r, are found (Fig. 3) [12]. Dynamics of $r$ follows that of $\rho$ but fluctuations in years are considerably smoothed down. Available data appear insufficient to recognize confident differences between ICC values at different plots or in years. Notwithstanding the lack of statistical safety in estimates obtained, a tendency is apparent in dynamics of variability components in the studied pine populations. Thus, the Snedekor estimate of ICC for the reference population C demonstrates fairly stable behavior within the observation period (Fig. 3): this index smoothly decreases from $5.3 \%$ to $-6.8 \%$ with an average value $\bar{r}=-0.1 \%$ and maximum amplitude $\Delta \mathrm{r}=12.1 \%$; whereas in two others populations, the values of $\mathrm{r}$ are very unsteady from year to year, and maximum amplitudes amount to $\Delta \mathrm{r} \approx 21.8 \%$ in both population B and A. Moreover, $\bar{r}=1.1 \%$ in population $\mathrm{B}$ and $\bar{r}=1.0 \%$ in population A are an order of magnitude as compared to population $\mathrm{C}$.

\section{CONCLUSION}

The significant increase in cytogenetic anomalies indicates that the tree populations at studied territories are experiencing some genotoxic exposure. The higher radioresistance of Scots pine seeds and increased level of cytogenetic variability means that adaptive processes in populations growing in the enterprise vicinity have not been completed yet, and the natural selection of the fittest genotypes is continuing. This is the regular result that the genotypically predetermined component is prevailing in total variability since levels of industrial impact in this region, in accordance with sanitary-hygienic monitoring data, are low and meet requirements of health safety. But nevertheless, there is a tendency to destabilizing dynamics and increasing average values of ICC under conditions of long man-caused impact on pine populations. A long generative cycle typical of most coniferous trees (over two years for Scots pine [26]) results in an accumulation of significant and observable DNA damage in the undifferentiated stem cells, even from exposure to low levels of anthropogenic contaminants. These 
latent cumulative damages become detectable as chromosome aberrations in first mitosis when seeds germinate. So, revealing effects of unfavorable environmental conditions is possible in wild populations even at fairly low level but prolonged technogenic impact, using the adopted approaches.

Whether natural ecosystems and communities have sufficient potential to stand against existing and growing anthropogenic influence, how serious and important for sustainability in descendants are adaptation processes and modifications of genetic structure in populations, - these are the problems that workers in ecology and population genetics have agitated by. These issues perception governs an urgency and necessity to develop special standards to limit industrial impact on nature. In this respect, presented results of cytogenetical variability and temporal dynamics analysis in anthropogenically affected natural populations are of obvious scientific interest.

\section{References}

[1] Shevchenko V.A., Pechkurenkov V.L. and Abramov V.I., Radiation genetics of natural populations: genetic consequences of the Kyshtym accident, (Nauka, Moscow, 1992).

[2] Glotov N.V., Russ. J. Ecol. 1 (1983) 3-10.

[3] Geras'kin S.A., Radiat. Biol. Radioekol. 35 (1995) 571-580.

[4] Prus-Glowacki W., Wojnicka-Poltorak A., Oleksyn J., Reich P.B., Water, Air, and Soil Pollution 116 (1999) 395-402.

[5] Theodorakis C.W., Ecotoxicology 10 (2001) 245-256.

[6] Wurgler F.E. and Kramers P.G., Mutagenesis 7 (1992) 321-327.

[7] Glotov N. V., Maximenko O.E. and Orlinskiy D.B., Russ. J. Ecol. 5 (1995) 344-346.

[8] Kryshev I.I. and Ryasantzev E.P., Ecological safety of nuclear fuel cycle industry in Russia, (IzdAT, Moscow, 2000).

[9] Geras'kin S.A., Zimina L.M., Dikarev V.G., Dikareva N.S., Zimin V.L., Vasiliyev D.V., Oudalova A.A., Blinova L.D., Alexakhin R.M., J. Env. Radioactivity 66 (2003) 171-180.

[10] Blinova L.D., "Littoral ecosystem radioecological monitoring at the region of atomic energy enterprises", International Symposium on Ionizing Radiation, Stockholm, 1996, B. Amiro, R. Avadhanula, G. Johansson, C-M. Larsson \& M. Lüning Eds, pp. 497-503.

[11] Draper N.R. and Smith H., Applied regression analysis (J. Wiley \& Sons, New York, 1981).

[12] Zhivotovsky L.A., Russ. J. Genet. 15 (1979) 1235-1242.

[13] Alieva I.B. and Vorobiev I.A., Tsitol. 31 (1989) 633-641.

[14] Micieta K. and Murin G., Water, Air, and Soil Pollution 104 (1998) 413-422.

[15] Bessonova V.P., Russ. J. Ecol. 23 (1992) 45-50.

[16] Valverde M., Trejo C. and Rojas E., Mutagenesis 16 (2001) 265-270.

[17] Hartwig A. and Schwerdtle T., Toxicol. Lett. 127 (2002) 47-54.

[18] Warr T., Parry E. and Parry J., Mutat. Res. 287 (1993) 29-46.

[19] Seoane A.I. and Dulout F.N., Mutat. Res. 490 (2001) 99-106.

[20] Cherezhanova L.V. and Alexakhin R.M., Russ. J. General Biol. 36, (1971) 303-311.

[21] Pitelka L.F., Trends Ecol. Evol. 3 (1988) 233-236.

[22] Macnair M.R., Trends Ecol. Evol. 2 (1987) 354-359.

[23] Antonovics J., Bradshaw A.D. and Turner R.G., Adv. Ecol. Res. 7 (1971) 1-85.

[24] Kalchenko V.A. and Fedotov I.S., Russ. J. Genet. 37 (2001) 427-447.

[25] Mittelsten-Scheid O., Afsar K. and Paszkowski J., Proc. Natl. Acad. Sci. USA 95 (1998) 632-637.

[26] Kozubov G.M. and Taskaev A.I., Radiobiological and radioecological studies of woody plants (Nauka, St Petersburg, 1994). 